\title{
Critical Analysis of Performance of Compression Ignition Engine for Biodiesel with Exhaust Gas Recirculation
}

\author{
M H Attal ${ }^{*}$ and A M Mahalle ${ }^{\ddagger}$ \\ †Mechanical Engieering, Sinhgad College of Engineering, Pune, Maharashtra, India \\ ‡General Engineering Department, LIT,Nagpur, Maharashtra, India
}

Accepted 01 Sept 2016, Available online 02 Sept 2016, Vol.6, No.5 (Oct 2016)

\begin{abstract}
Petroleum reserves are rapidly and continuously depleting due to this there is an urgent need to find alternative energy resources which is primarily attributed to combustion of fossil fuels. In last couple of decades, biodiesel has emerged as the most important alternative fuel to mineral diesel. Numerous experimental investigations have confirmed that biodiesel results in improved engine performance, lower emissions, particularly lower particulate mass emissions is therefore relatively more environment friendly fuel, being renewable in nature. Environmental and health effects of particulates are not simply dependent on the particulate mass emissions but these change depending upon varying physical and chemical characteristics of particulates. This paper presents an exhaustive experimental analysis of Compression ignition (CI) engine. The effect of biodiesel and its blends on exhaust particulate's physical characteristics. Control of particulate emissions using exhaust gas recirculation (EGR) with the use of biodiesel has been critically analyzed and included in this article.
\end{abstract}

Keywords: EGR, Biodiesel, Size-number distribution, Particulate, Transesterification

\section{Introduction}

Higher efficiency, reliability and fuel economy makes diesel engines better choice than spark ignition (S.I.) engine and hence they are used widely in commercial applications. Exhaust gas emitted from compression ignition (C.I.) engine is a mixture of many undesirable constituents known as pollutants. Also there is continuous depletion of fossil fuels. Environmental pollution is becoming a serious problem. All these have caused researchers to focus their interest on the study of alternative fuels for Internal Combustion engines. The alternative fuels are alcohols, biodiesel, natural gas, etc. Fuels derived from renewable biological resources for use in diesel engines are known as biodiesel. Biodiesel is environmentally friendly fuel having combustion properties somewhat similar to petrol-diesel. Biodiesel is a biodegradable and nontoxic diesel fuel which consists of long polymeric chains of alkyl esters. Various researchers have conducted experiments to study the performance and emission characteristics of diesel engine when vegetable oils, blends of vegetable oil and its derivatives are used as fuel and it has been found to be economical and competitive compared to standard diesel. Biodiesel can be blended at any proportion in diesel fuel to be used in diesel engines with small or no modification. In order to ensure proper performance and quality,

*Corresponding author: M H Attal biodiesels are produced through the transesterification process to meet ASTM D6751 standard. The 'National Bio fuel Policy' desires to meet $20 \%$ of India's diesel requirement.

Biodiesel gives comparatively lower emission of particulate matter (PM), Carbon monoxide (CO), and Hydrocarbon (HC) with small disturbance in engine performance and fuel consumption. Many researchers have found that biodiesel fueled engine produce higher $\mathrm{NO}_{\mathrm{x}}$ emission compared to diesel. EGR is an effective technique to reduce $\mathrm{NO}_{\mathrm{x}}$ emission from the diesel engine. Controlling the $\mathrm{NO}_{\mathrm{x}}$ emissions primarily requires reduction of in-cylinder temperatures. However, the application of EGR results in higher fuel consumption, also EGR increases $\mathrm{HC}, \mathrm{CO}$, and $\mathrm{PM}$ emissions with slight increase in specific fuel consumption. The PM particle size dissemination is required to analysis as size distribution is directly concern with human health. The particle sizes are generally divided into two modes: the nucleation mode and the accumulation mode. Nucleation mode particles increase with biodiesel percentage in diesel engine.

Agriculture base Country like India having vast vegetation and land availability, biodiesel have come up as a promising alternative fuel. Many feed stocks for biodiesel viz. edible as well as non edible vegetable oils such as rapeseed, soybean, palm, sunflower, coconut, linseed, etc. have been exploited for use as alternate fuel for diesel engine (Nahar N.M., 2005) 
Implementation of non-edible base biodiesel in India will lead to many advantages like green cover to wasteland, support to agriculture and rural economy and reduction in dependence on imported crude oil and reduction in air pollution (Rao $\mathrm{T}$ Venkateswara, 2013).With the use of biodiesels it becomes essential to know the performance of the diesel engine for various proportions of blends, injection pressures and compression ratios. This requirement can be met by performing comprehensive tests for investigating performance and emissions of the diesel engine operating on the alternative fuels. The present work investigates the suitability of non-edible oil methyl esters (biodiesel) as alternate fuels by evaluating the effect of their use for diesel engine in terms of performance and exhaust emissions.

A.E. Atabani et.al. (2013) have laid emphasis on various aspects associated to non-edible oil feed stocks for the biodiesel production. They have reviewed various facets such as non-edible oil resources, advantages of non- edible oils, properties and characteristic of non-edible biodiesel and finally the engine performance and emission characteristics. The authors indicated that there is a huge chance to produce biodiesel from non-edible sources in the future. Lin et.al. (2009) have reported successful production of biodiesel by transesterification of crude Rice bran oil (RBO). Later according to ASTM D675102 and DIN V51606 standards for biodiesel the properties of prepared RBO biodiesel were studied and compared which agreed well within the parameters imposed. Attal M H et.al (2014) has studied the performance and emission characteristics of a three cylinder Compression ignition Engine. It is seen that biodiesels obtained from Kokam oil and Rice bran oil could be used effectively as an alternative fuels in existing diesel engines without any engine hardware modifications.

Hussain J. et al. (2012) have studied the Effect of Exhaust Gas Recirculation (EGR) on performance and emission characteristics of a three cylinder direct Injection Compression ignition Engine. It is seen that thermal efficiency is slightly increased and BSFC is decreased at lower loads with EGR compared to that without EGR. At higher loads, increased rate of EGR reduces $\mathrm{NO}_{\mathrm{x}}$ to a great extent but disturbs engine performance and emissions. They concluded that higher rate of EGR can be applied at lower loads. It is noted that that $15 \%$ EGR rate is found effective to reduce $\mathrm{NO}_{\mathrm{x}}$ emission substantially without deteriorating engine performance in terms of thermal efficiency, BSFC, and emissions.

An Puzun et al. (2011) studied characteristics of particle size distributions in common rail diesel engine using biodiesel blends. They concluded that the number of particles in nucleation mode increases with increase of biodiesel and the accumulation mode particles of a size $>50 \mathrm{~nm}$ decrease. With increase in load, nucleation mode particles decrease. Most of the particulate emissions are less than $300 \mathrm{~nm}$.
M. Kassaby et al.(2011) studied the effect of compression ratio on an engine fueled with waste oil produced biodiesel/diesel fuel. Biodiesel can be blended up to $20 \%$ at any compression ratio with safety consideration. BSFC increases and BTE decreases as biodiesel increases. It is seen that BSFC decreases and BTE increases as compression increases. $\mathrm{CO}_{2}$ and $\mathrm{NO}_{\mathrm{x}}$ increased with compression ratio. Increase in the compression ratio improved the performance and cylinder pressure of the engine and it has shown more benefits with biodiesel than that of diesel.

Y. Park and C. Bae (2011) have experimentally investigated the effects of high/low pressure EGR proportion in a passenger car diesel engine. It is found that the intake manifold temperature showed decreasing trend as the LP EGR portion increased because the LP EGR was cooled down more than the HP EGR due to longer supply line. The VGT nozzle opened more widely to maintain the boost pressure, which resulted into the lower BSFC. The pumping loss showed a decreasing order with the increase of the LP EGR portion. $\mathrm{NO}_{\mathrm{x}}$ emissions showed good improvement when increasing the LP EGR.

W. Zhang et al. (2011) studied the influence of EGR and oxygen-enriched air on diesel engine NO-Smoke emission and combustion characteristic. The authors have noted that proper combination of EGR rate and oxygen concentration can achieve low NO-Smoke emission. Smoke opacity decreases effectively in case of oxygen-enriched combustion of diesel engines. The numerical simulation results indicate that oxygen enriched combustion suppress HACA reactions and is reducing the formation of large molecule PAHs.

Agarwal Avinash Kumar and Dhar Atul (2013) experimentally investigated performance, emission and combustion characteristics of Karanja oil blends fuelled DICI engine. Calorific value of Karanja oil is lower compared to mineral diesel. Therefore with increasing proportion of Karanja oil in the blends BSFC increases. Thermal efficiency of Karanja blends was lower than mineral diesel. Thermal efficiency of only K10 at lower engine loads was observed to be close to that of mineral diesel. $\mathrm{CO}_{2}$ emissions for all Karanja oil blends were significantly higher than mineral diesel.

Agarwal Avinash Kumar and K. Rajamanoharan (2009) studied performance and emissions of Karanja oil and its blends in a single cylinder agricultural diesel engine. They found that thermal efficiency of the engine with preheated oil blends is nearly $30 \%$ and for lower blends (unheated) such as K10, K20 and K50, it was $24-27 \%$. The brake specific fuel consumption and brake specific energy consumption of the engine with preheated lower blends showed an improved trend.

Rahman M. M. et al.(2013) evaluated alternative fuels effect on particle emission from a common-rail diesel engine. Up to $30 \%$ energy substitution by ethanol reduced $\mathrm{PM}$ and $\mathrm{PN}$ consistently. Biodiesel reduced PM most among all used alternative fuels. canola biodiesel increased PN and tallow biodiesel 
reduced PN with $15 \mathrm{~nm}$ reduction in particle median diameter.

Xinling Li et al.(2014)studied exhaust gas recirculation (EGR) impact on soot reactivity from a diesel engine. Combustion duration increases as EGR rate increases. BSFC and soot emission also increases with EGR rate. Highly ordered graphitic structure and low OC fraction in the particle sample are responsible for the decrease of soot reactivity with the increase of EGR at high load.

\section{Fuel Preparation}

Biodiesel can be produced from vegetable oils, animal oils/fats and waste cooking oils.Amongst all methods almost all biodiesel is produced using transesterification as it is the most economical process requiring only low temperatures and pressures and producing a high conversion yield. The Transesterification process is the reaction of a triglyceride (fat/oil) with an alcohol to form esters and glycerol.

\subsection{Transesterification}

Vegetable oil is considered as feedstock for the biodiesel production and the method of biodiesel production is known as transesterification (N.M. Nahar,2005). A triglyceride has a glycerine molecule as its base with three long chain fatty acids attached. The characteristics of the fat are determined by the nature of the fatty acids attached to the glycerine. The problems with substituting triglycerides for diesel fuels are mostly associated with their high viscosities, low volatilities. The nature of the fatty acids can in turn affect the characteristics of the biodiesel. During the esterification process, the triglyceride is reacted with alcohol in the presence of a catalyst, usually a strong alkaline like sodium hydroxide or potassium hydroxide. The alcohol reacts with the fatty acids to form the mono-alkyl ester, or biodiesel and crude glycerol. Commonly methanol or ethanol is used as alcohol. Methanol produces methyl esters while ethanol produces ethyl esters. The vegetable oil derivatives viz. mono-alkyl esters approximate the properties compatible with the diesel fuels.

The transesterification reaction is given below

$$
\text { Catalyst }
$$

Oil or Fat + Alcohol Glycerin + Biodiesel

Transesterification is a chemical process of transforming large, triglyceride molecules of vegetable oils and fats into smaller molecules, similar in size to the molecules of the species present in diesel fuel (Nahar N.M., 2005).

\subsection{Preparation of Blends}

At present the amount of biodiesel available is less than that of diesel. The biodiesel blended with diesel by volume as B10 (10\% undi biodiesel \& 90\% diesel fuel), B20 (20\% undi biodiesel \& 80\% diesel fuel), B30 (30\% undi biodiesel \& 70\% diesel fuel), B40 (40\% undi biodiesel \& 60\% diesel fuel), B100 (100\% undi biodiesel \& $00 \%$ diesel fuel).

\section{Engine Setup Descriptions}

Fig. 2 represents schematic diagram of diesel engine setup to carry out test. The engine used in present study is single cylinder four stroke naturally aspirated water cooled diesel engine.

The test setup is shown Figure 2. The components in test setup are 1. Engine 2. Manometer 3. Air Box 4. Air Filter 5. FuelTank 6. Burette7. Exhaust Pipe8. Alternator 9. EGR Pipe 10. EGR valve 11. Exhaust Gas Analyser 12. Exhaust Valve 13. Dilution Pipe14. Thermocouple for mixture 15. Thermocouple for Exhaust Gas

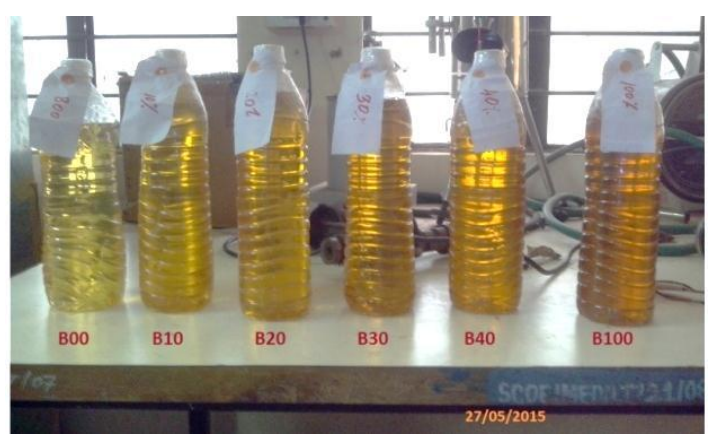

Figure 1 : Blends of Undi Oil Biodiesel

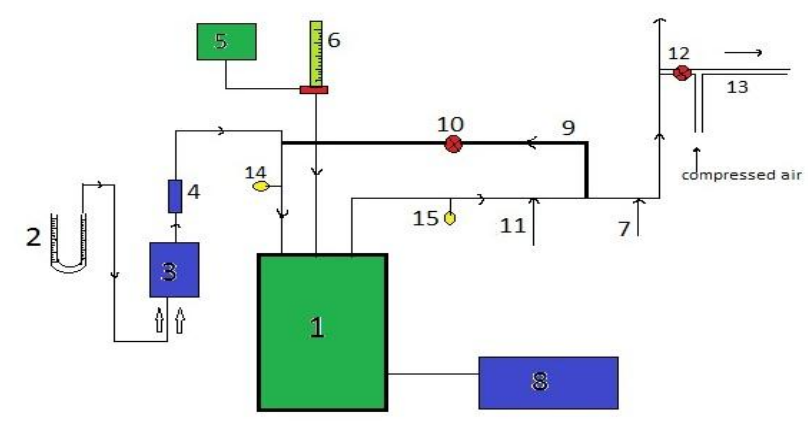

Figure 2 : Schematic of Experimental Setup

Engine technical specifications are shown in table 2.

Table 1: Engine Specifications

\begin{tabular}{|c|c|}
\hline Make & Kirloskar AV1 Engine \\
\hline No. of Cylinders & 1 \\
\hline No. of Strokes & 4 \\
\hline Bore x Stroke (mm) & $80 \times 110$ \\
\hline $\begin{array}{c}\text { Fuel Injection Timing }\left({ }^{\circ} \mathrm{CA}\right. \\
\text { BTDC) }\end{array}$ & 23 \\
\hline Compression Ratio & $16.5: 1$ \\
\hline Rated Power Output (KW) & $3.7(5 \mathrm{hp})$ \\
\hline Rated Speed (rpm) & 1500 \\
\hline Displacement $\left(\mathrm{cm}^{3}\right)$ & 553 \\
\hline Type of Fuel Injection & Direct Injection \\
\hline Type of cooling & Water cooled \\
\hline
\end{tabular}


To carry out the present study, a diesel engine coupled with an alternator is selected. From the head difference in the manometer, air flow rate is calculated. The fuel consumption of an engine is measured by determining the time required for consumption of a given volume of fuel.

\section{Results and discussion}

The test has been conducted on single cylinder diesel engine using pure diesel and biodiesel blends. The blends used are B10, B20, B30, B40 and B100. The experimental results have been plotted as below. Effect of Exhaust Gas Recirculation (EGR) rate is also studied on engine performance and emission parameters. Comparison of experimental results is done for individual fuel i.e. pure diesel and above mentioned blends.

\subsection{Average Performance Impact}

Figure 3 represents variation of brake thermal efficiency and brake specific fuel consumption of undi biodiesel blend compared with petroleum diesel. For B10 blend, BTE decreases by 3.03\% and for B100 blends, BTE decreases by $19.45 \%$. Minimum variation in BTE is for B20 blend with value $2.55 \%$ and maximum variation is for B100 with value $19.45 \%$. As percentage of biodiesel is increased from 10 to 100 , BSFC increases by $4.86 \%$ to $37.03 \%$. Maximum variation in $\mathrm{BSFC}$ is for $\mathrm{B} 100$ blend having value $37.03 \%$ compared with pure diesel.

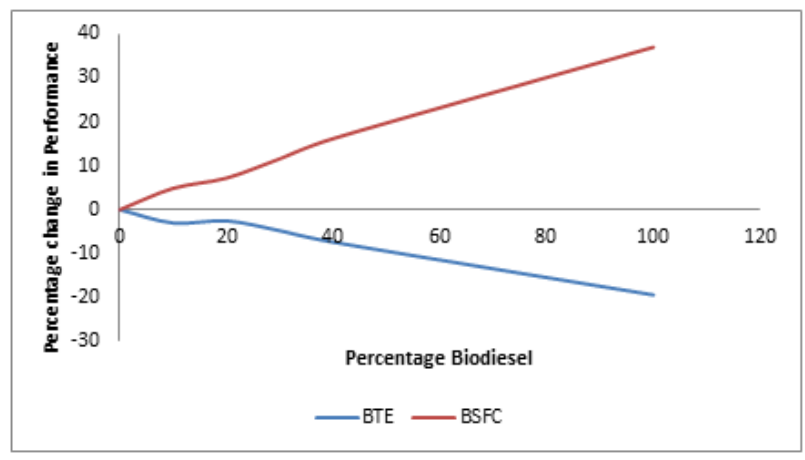

Figure 3: Average Performance Impact of Undi Biodiesel on Diesel Engine

\subsection{Average Emission Impact}

Figure 4 represents variation of engine emission of undi biodiesel blend compared with petroleum diesel. As percentage of biodiesel is increased from 10 to 100 , $\mathrm{NO}_{\mathrm{x}}$ emission increase by $3.38 \%$ to $56.61 \%$ and Smoke percentage decreases by $4.87 \%$ to $24.39 \%$. HC emissions decrease by $5.26 \%$ to $26.31 \%$ with biodiesel variation from $10 \%$ to $100 \%$. Carbon dioxide increases by $5.55 \%$ to $72.22 \%$. Maximum variation in $\mathrm{NOx}$, smoke, $\mathrm{HC}, \mathrm{CO}$ and $\mathrm{CO}_{2}$ is $56.61 \%, 24.39 \%, 26.32 \%$, $60 \%$ and $16.67 \%$ respectively.
4.3 Average Impact of EGR Percentage on Performance and Emission of Diesel Engine with Diesel Engine with Pure Diesel as Fuel

Figure 5 shows average impact of EGR percentage on diesel engine performance using petroleum diesel as fuel. As EGR percentage is varied from $10 \%$ to $30 \%$, BTE decreases from $1.40 \%$ to $12.75 \%$ and BSFC increases by $1.94 \%$ to $15.75 \%$.

For variation of EGR form $10 \%$ to $30 \%$, NOx emission decrease by $14.57 \%$ to $54.91 \%$, HC emission increase by $5.26 \%$ to $26.31 \%$ and smoke percentage increase by $2.43 \%$ to $9.75 \%$. CO emissions increase from $11.11 \%$ to 66.665 and $\mathrm{CO}_{2}$ emission decrease by $3.22 \%$ to $12.90 \%$.

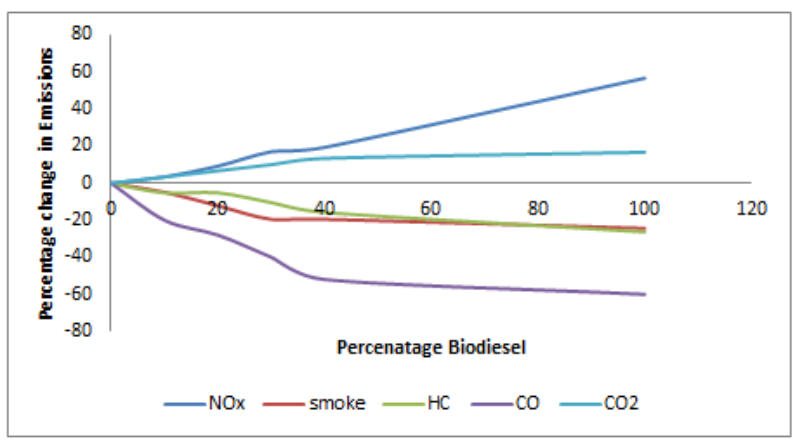

Figure 4 :Average Emission Impact of Undi Biodiesel on Diesel Engine

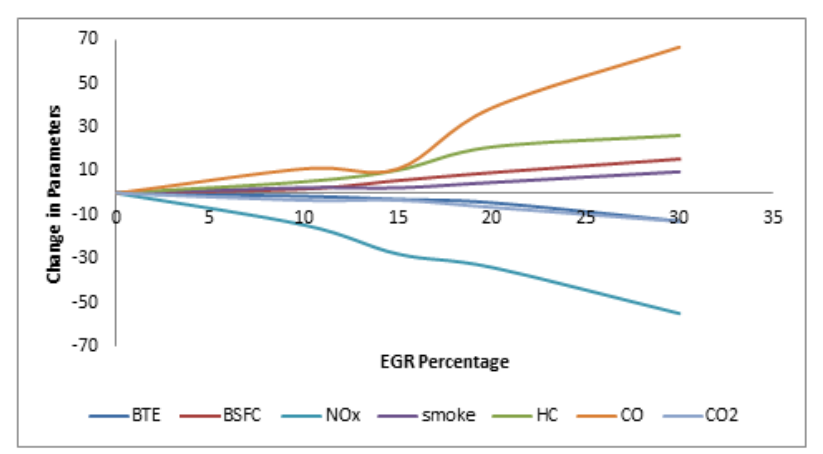

Figure 5: Average Impact of EGR Percentage on Diesel Engine with Pure Diesel as Fuel

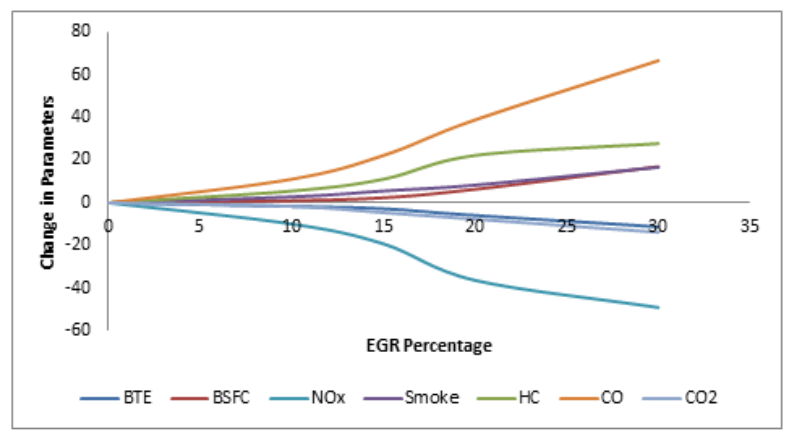

Figure 6: Average Impact of EGR Percentage on Diesel Engine with B20 Blend as Fuel 
4.4 Average Impact of EGR Percentage on Performance and Emission of Diesel Engine with B20 Blend as Fuel

Figure 9 shows average impact of EGR percentage on diesel engine performance using B20 blend as fuel. As EGR percentage is varied from $10 \%$ to $30 \%$, BTE decreases from $1.65 \%$ to $11.27 \%$ and BSFC increases by $1.01 \%$ to $16.95 \%$. For variation of EGR form $10 \%$ to $30 \%$, NOx emission decrease by $9.93 \%$ to $49.07 \%$, HC emission increase by $5.55 \%$ to $27.77 \%$ and smoke percentage increase by $2.73 \%$ to $16.66 \%$. CO emissions increase from $11.11 \%$ to 66.665 and $\mathrm{CO}_{2}$ emission decrease by $1.67 \%$ to $13.85 \%$.

\section{Conclusion}

The test has been carried out on diesel engine using blends B0, B10, B20, B30, B40 and B100 and performance and emission parameters are plotted for all blends. Comparing brake thermal efficiency and $\mathrm{NO}_{\mathrm{x}}$ emission with that of pure diesel it is found that percentage change in BTE of B20 blend is 2.55\% and $\mathrm{NO}_{\mathrm{x}}$ emission increases by $9.15 \%$.

From experimental work it is seen that, for $10 \%$ EGR rate, BTE for diesel, B10, and B20 blends decrease by $1.40 \%, 2.43 \%$ and $1.65 \%$ respectively. Also, $\mathrm{NO}_{\mathrm{x}}$ emission decrease by $14.57 \%, 2.29 \%$, and $9.93 \%$ respectively. Hence, $10 \%$ EGR rate gives optimized engine performance.

For B20 blend and using 10\% EGR rate, it is concluded that BSFC increases by $1.01 \%$, HC emission by $5.55 \%$ and smoke increases by $2.77 \%$ compared with that of $\mathrm{B} 20$ blend with $0 \%$ EGR rate. Hence, compared with other EGR rates, $10 \%$ EGR rate gives optimized engine performance.

\section{Acknowledgment}

Author is very thankful to Indian bio-diesel Corporation, Baramati for providing there testing facility for production of bio-diesel.

\section{Reference}

M. MohibbeAzam, Waris Amtul, Nahar N.M., (2005), Prospects and potential of fatty acid methyl esters of some non-traditional seed oils for use as biodiesel in India, Biomass and Bioenergy 29 293-302.

Rao T Venkateswara, Rao G Prabhakara and Reddy K Hema Chandra, (2013), Performance and emission analysis of Pongamia, jatropha and neem methyl Esters as biodiesel in a C.I engine, International Journal of Mechanical Engineering \& Robotics Research, Vol. 2, No. 3.

A.E. Atabani, A.S.Silitonga, H.C.Ong, Mahlia T.M.I., H.H.Masjuki, Irfan AnjumBadruddin, H.Fayaz,(2013). Nonedible vegetable oils: a critical evaluation of oil extraction, fatty acid compositions, biodiesel production, characteristics, engine performance and emissions production, Renewable and Sustainable Energy Reviews 18
Lin Lin, Dong, Dong Ying, SumpunChaitep, SaritpornVittayapadung,(2009). Biodiesel production from crude rice bran oil and properties as fuel, Applied Energy 86, 681-688.

Attal M M, Dave Chirag, Mahalle A M. ,(2014). Experimental Investigation on Performance of a Diesel Engine using GarciniaIndica (Kokam) and Rice Bran Oil based Biodiesels as Fuels,IOSR Journal of Mechanical and Civil Engineering, Volume 11, Issue 5 Ver. II,pp 01-07

JaffarHussain, K. Palaniradja, N. Alagumurthi, R. Manimaran,(2012). Effect of Exhaust Gas Recirculation (EGR) on Performance Emission characteristics of a Three Cylinder Direct Injection Compression Ignition Engine, Alexandria Engineering Journal,51, pp.241-247.

An Puzun, Sun Wanchen, LiGuoliang, Tan Manzhi, Lai Chunjie, Chen Shibao,(2011) Characteristics of Particle Size Distributions About Emissions in A Common-rail Diesel Engine with Biodiesel Blends, Procedia Environmental Sciences 11, pp 1371 - 1378.

Mohammed EL_Kassaby, Medhat A. Nemitallah,(2013).Studying the effect of compression ratio on an engine fueled with waste oil produced biodiesel/diesel fuel, Alexandria Engineering Journal , 52, pp.1-11.

Youngsoo Park, ChoongsikBae,(2014) Experimental study on the effects of high/low pressure EGR proportion in a passenger car diesel engine, Applied Energy, 133 pp. 308316.

Wei Zhang , Zhaohui Chen, Weidong Li , GequnShu b, Biao Xu b, YinggangShen, (2013) Influence of EGR and oxygenenriched air on diesel engine NO-Smoke emission and combustion characteristic', Applied Energy ,107, pp.304314.

Agarwal Avinash Kumar, Dhar Atul,(2013), Experimental investigations of performance, emission and combustion characteristics of Karanja oil blends fuelled DICI engine, Renewable Energy 52 pp 283-291.

Agarwal Avinash Kumar, K. Rajamanoharan, (2009) Experimental investigations of performance and emissions of Karanja oil and its blends in a single cylinder agricultural diesel engine, Applied Energy 86, pp.106-112.

Rahman M. M., S. Stevanovic, R.J. Brown, Z. Ristovski, (2013) Influence of different alternative fuels on particle emission from a turbocharged common-rail Diesel engine", Procedia Engineering 56 pp. 381 - 386.

Xinling Li, Zhen Xu, Chun Guan, Zhen Huang, (2014) Impact of exhaust gas recirculation (EGR) on soot reactivity from a diesel engine operating at high load, Applied Thermal Engineering,68 pp.100-106.

Attal M H, Mahalle A M , (2015), The Emissions Analysis of Diesel Engine Using GarciniaIndica and Rice Bran Oil Based Methyl Esters as Fuels with an ANN Approach, International Journal of Innovative and Emerging Research in Engineering

Sutar Nikhil , M.H. Attal (2016) ,Performance Evaluation of C.I. engine with change in different engine variables and using methyl ester of Argemone Mexicana,International Journal of Current Engineering and Technology, Special Issue-5 